\section{COMESCAL: A microcomputer program for testing axioms and finding scale values for conjoint measurement data}

\section{JOSEF LUKAS \\ Universität Regensburg, Regensburg, West Germany}

Conjoint measurement analysis (Luce \& Tukey, 1964) usually starts out with an empirical weak order $\gtrsim$ over a set of stimuli $\mathbf{S}=\mathbf{A} \times \mathbf{X}$, where $\mathrm{a}$ and $\mathrm{x}$ are two components of a stimulus $s=(a, x)$. For example, assume $s$ to be a stimulus light patch with luminance a and duration $x$, and $\geq$ an order relation "at least as bright as" established by the subject in an experiment. In order to represent the empirical ordering by a sum of numerical functions of each of the components, one has to find scale values $\phi_{1}(a)$ and $\phi_{2}(x)$ such that for all $a, b \in A$ and $\mathrm{x}, \mathrm{y} \in \mathrm{X}$

$$
\phi_{1}(\mathrm{a})+\phi_{2}(\mathrm{x}) \geq \phi_{1}(\mathrm{~b})+\phi_{2}(\mathrm{y}) \text { iff }(\mathrm{a}, \mathrm{x}) \geq(\mathrm{b}, \mathrm{y})
$$

(see Krantz, Luce, Suppes, \& Tversky, 1971, for a detailed discussion). To solve this problem, the order relation has to be transformed into a set of inequalities, which may be solved by one of the usual algorithms, for example, ORDMET by McClelland and Coombs (1975) or ORDMET2 by Lehner and Noma (1980). These programs generate a description of the complete solution space for a given system of inequalities. If a solution does not exist, then the programs try to find scale values representing the data approximately.

Psychological research, however, is often concerned with testing structural properties of data, rather than with finding only scale values. In the context of additive conjoint measurement, experimental tests have concentrated on the independence axiom and the double cancellation axiom, as pointed out by Roberts $(1979$, p. 221$)$. Computer programs for checking these axioms have been published by Holt and Wallsten (1975), Person (1977), Ullrich, Cummins, and Walkenbach (1978), and others. Unfortunately, independence and double cancellation are not sufficient for an additive representation to exist. Higher order cancellation axioms have to be added (Scott, 1964), but these imply an infinite number of conditions to be checked and thus they are not directly testable. Although seldom violated in small designs, as shown in a simulation study by McClelland (1977) using up to $4 \times 4$ matrices, they become more important in larger designs. Even if finding numerical scale values is not the main concern in an experiment, a scale construction routine might be necessary to provide an indirect test for the

The author's mailing address is: Lehrstuhl für Psychologie Prof. Dr. Drösler, Universität Regensburg, Postfach 397, D-8400 Regensburg, West Germany. higher order cancellation axioms and to decide whether or not the data are additive.

Consequently, COMESCAL, the program described here, combines axiom checking and scale construction, thus providing a complete data-analysis program for the additive model (1). Unlike all the programs mentioned above, COMESCAL is designed to run on a microcomputer to meet the special requirements for direct use in the experimental laboratory.

Description. The program is written in Microsoft BASIC and runs under the CP/M operating system with $48 \mathrm{~K}$ of memory. Input to the program is a $\mathrm{m} \times \mathrm{n}$ rank order matrix $\mathrm{R}$ with $\mathrm{r}_{\mathrm{ij}}$ indicating the rank order of stimulus $\left(a_{i}, x_{j}\right)$ and monotonically increasing with both $i$ and $\mathrm{j}$ (identical rows and/or columns should have been canceled before any processing). Whenever columns or rows cannot be ordered in a way such that this condition is fulfilled, the two components are not independent and $\mathrm{B}$ is not decomposable into additive scales. This condition is checked by the data-reading routine.

The first step in the program is a check of the doublecancellation condition:

$$
\text { if }(a, x) \geq(b, y) \text { and }(b, z) \geq(c, x) \text { then }(a, z) \geq(c, y)
$$

for all $a, b, c \in A$ and $x, y, z \in X$. All $3 \times 3$ submatrices of $B$ causing a violation of this condition are printed, and statistics are provided about the number of submatrices tested and the number of violations. If there are no violations, the set of inequalities defined by the rank-order matrix is generated and reduced to a minimal system of inequalities, which suffices to determine the empirical order. This reduction to "basic inequalities," according to Sherman (1977), brings the calculations down to proportions manageable by fairly small microcomputers. The system of inequalities is then solved using an algorithm of Chernikova (see Lehner \& Noma, 1980, and Sherman, 1977, for detailed descriptions). If there is a solution, then the complete solution space is described by a $u \times v-$ matrix $C$, where $v=n+m-2$ and $u$ depends on the data and determines the size of the solution cone. If $\phi_{1}\left(a_{1}\right)$ and $\phi_{2}\left(x_{1}\right)$ both are set to 0 , then for every vector $\underline{\lambda}=\left(\lambda_{1}, \ldots, \lambda_{u}\right)$ with $\lambda_{i}>0$,

$$
\underset{\sim}{C} \cdot \underset{\sim}{\lambda}=\left[\phi_{1}\left(\mathrm{a}_{2}\right), \phi_{1}\left(\mathrm{a}_{3}\right), \ldots, \phi_{1}\left(\mathrm{a}_{\mathrm{n}}\right), \phi_{2}\left(\mathrm{x}_{2}\right), \ldots, \phi_{2}\left(\mathrm{x}_{\mathrm{m}}\right)\right]
$$

defines scale values satisfying condition (1). For a given $\lambda$, the scale values are unique up to addition of a constant number for each of the two components. If $\phi_{1}$ and $\phi_{2}$ is a solution for (1), then $\phi_{1}^{\prime}:=\phi_{1}+c_{1}$ and $\phi_{2}{ }^{\prime}:=$ $\phi_{2}+c_{2}$ is another solution for any $c_{1}, c_{2} \in R e$.

Limitations. The program finds only exact solutions. No data-fitting procedures are implemented. The standard version allows processing of rank-order matrices not larger than $10 \times 10$, that is, an ordering of not more than about 100 stimuli. This boundary is due only to memory 
limitations (48K). The program can easily be adapted to larger stimulus sets and computer facilities. With the possible exception of statements for (optional) output on a line printer or (optional) data input from disk, the program does not depend on any special features of Microsoft BASIC or CP/M.

Availability. A listing of the program and detailed instructions for matching the dimension of arrays to the size of the stimulus set and available core memory may be obtained without charge from the author.

\section{REFERENCES}

Holt, J. O., \& Wallsten, T. S. (1975). A users manual for CONJOINT: A computer program for evaluating certain conjoint measurement axioms. Catalogue of Selected Documents in Psychology, $5,317$.

Krantz, D. H., Luce, R. D., Suppes, P., \& TVersky, A. (1971). Foundations of measurement, (Vol. 1). New York: Academic Press. LeHNer, P. E., \& Noma, E. (1980). A new solution to the problem of finding all numerical solutions to ordered metric structures. Psychometrika, 45, 135-137.
LUCE, R. D., \& TUKEY, J. (1964). Simultaneous conjoint measurement: A new type of fundamental measurement. Journal of Mathematical Psychology, 1, 1-27.

MCCLELLAND, G. (1977). A note on Arbuckle and Larimer, "The number of two-way tables satisfying certain additivity axioms.' Journal of Mathematical Psychology, 15, 292-295.

MCClelland, G. H., \& CoOmbs, C. H. (1975). ORDMET: A general algorithm for constructing all numerical solutions to ordered metric structures. Psychometrika, 40, 269-290.

Person, H. B. (1977). SCJM: A stochastic conjoint-measurement diagnosis program. Journal of Marketing Research, 14, 98-99.

RoBERTs, F. S. (1979). Measurement theory with applications to decision making, utility, and the social sciences. Reading, MA: AddisonWesley.

ScotT, D. (1964). Measurement models and linear inequalities. Journal of Mathematical Psychology, 1, 233-247.

SHERMAN, B. F. (1977). An algorithm for finite conjoint additivity. Journal of Mathematical Psychology, 16, 204-218.

Ullrich, J. R., Cummins, D. E., \& Walkenbach, J. (1978). PCJM2: A program for the axiomatic conjoint measurement analysis of polynomial composition rules. Behavior Research Methods \& Instrumentation, 10, 89-90.

(Revision accepted for publication January 3, 1985.) 